\title{
Methylation of DNA in megaloblastic anaemia
}

\author{
J Perry, I Chanarin, R Deacon, M Lumb
}

\begin{abstract}
Methylation of cytosine residues in DNA samples, collected before and serially after cobalamin treatment from patients with cobalamin deficiency, was studied using restriction endonucleases $\mathrm{Hpa} I I$ and $M s p I$ and an $\varepsilon$ globin gene probe. There was no evidence of hypomethylation in any of the samples. It was concluded that although hypomethylation of metabolites such as choline occurs, that of DNA is preserved in megaloblastic anaemia.
\end{abstract}

There are two de novo pathways for the synthesis of methionine in mammals. Both involve the transfer of a methyl group to homocysteine to yield methionine. In one pathway the methyl group is donated by betaine and in the second it is donated by 5-methyltetrahydrofolate. Cobalamin is an intermediary in the second reaction, the methyl group from methylfolate being transferred to cobalamin to yield methylcobalamin before being transferred to homocysteine. The enzyme is methionine synthetase. Methionine in turn is converted into $S$-adenosylmethionine and this is the principal transmethylating agent in mammals. It provides methyl group in the synthesis of choline as well as for methylation of cytosine residues in DNA. Impaired methylation in cobalamin deficiency was first shown in $1953^{1}$ and has been confirmed many times since, most recently in animals whose cobalamin had been inactivated by exposure to the anaesthetic gas nitrous oxide. ${ }^{2}$

About $5 \%$ of the cytosine residues in DNA are normally methylated. This is of particular interest in relation to megaloblastic anaemia because hypomethylation is a possible explanation for two unexplained phenomena in megaloblastic anaemia. One is the noticeably increased activity of a wide range of enzymes, the best studied being lactic acid dehydrogenase. Within a few days of treatment with the deficient vitamin the activity of these enzymes returns to normal. Enzyme activity is regulated by the state of methylation of DNA, being completely inactive when fully methylated (as with inactivation of one of the $\mathrm{X}$ chromosomes in all cells in women), or increasingly active when DNA is hypomethylated. ${ }^{3}$ The other phenomenon is the presence of megaloblasts. It is presumed that megaloblasts occur as a result of impaired coiling of DNA. With plasmid DNA, hypomethylation is accompanied by impaired coiling of DNA strands. ${ }^{4}$ Hoffbrand and Pegg reported that there was no change in 5 -methylcytosine concentrations in DNA in megaloblastic anaemia, ${ }^{5}$ but Karasawa et al reported a significant fall in DNA methylation in pernicious anaemia. ${ }^{6}$

\section{Methods}

The activity of two restriction enzymes that cleave DNA at cytosine, cytosine, guanine, guanine (CCGG) sequences were studied. $M s p$ I cleaves all such sites but $H p a I I$ will only cleave CCGG sequences when either both or just the internal cytosine is methylated. An $\varepsilon$ globin gene probe, kindly donated by $\mathrm{Dr} J \mathrm{M}$ Old of Oxford, was used.

Six patients with pernicious anaemia were studied. Their haemoglobin concentrations ranged from 5.6 to $10.6 \mathrm{~g} / 1$ and all had grossly megaloblastic marrows. DNA was prepared from peripheral blood leucocytes collected before and every two to three days after treatment with cobalamin for up to three weeks. DNA was also extracted from the marrow of three of these patients as well as from two normoblastic marrows.

DNA was extracted from peripheral blood, essentially as described by Maniatis et $a l,{ }^{7}$ and from air-dried bone marrow slides by the method of Fey et al. ${ }^{8}$ The DNA was digested firstly by the restriction endonuclease Hind $I I I$, followed by digestion with a fivefold excess of the restriction endonucleases $H p a I I$ or $M s p$ $I$, according to the manufacturer's instructions (Boehringer Mannheim; East Sussex, England). The restriction fragments were electrophoresed in $0.9 \%$ agarose gels and the DNA transferred to nitrocellulose membranes (Hybond C; Amersham International, England) using Southern blotting. ${ }^{9}$ The membranes were then hybridised to a ${ }^{32 p}$-nick translated $\varepsilon$ globin gene probe and autoradiographed at $-70^{\circ} \mathrm{C}$, with intensifying screens, for two to 14 days.

\section{Results}

The figure shows the autoradiograph of DNA from two patients digested with Hind III and Hpa II and hybridised to the ${ }^{32 p}$-labelled $\varepsilon$ globin probe. Most of the DNA that hybridised to the probe was 7.5 kilobase pairs in length before cobalamin treatment and this remained unchanged in all the samples tested after treatment. There was therefore no change in the number of cytosine sites methylated throughout the period of study.

Similar results were obtained with the other 


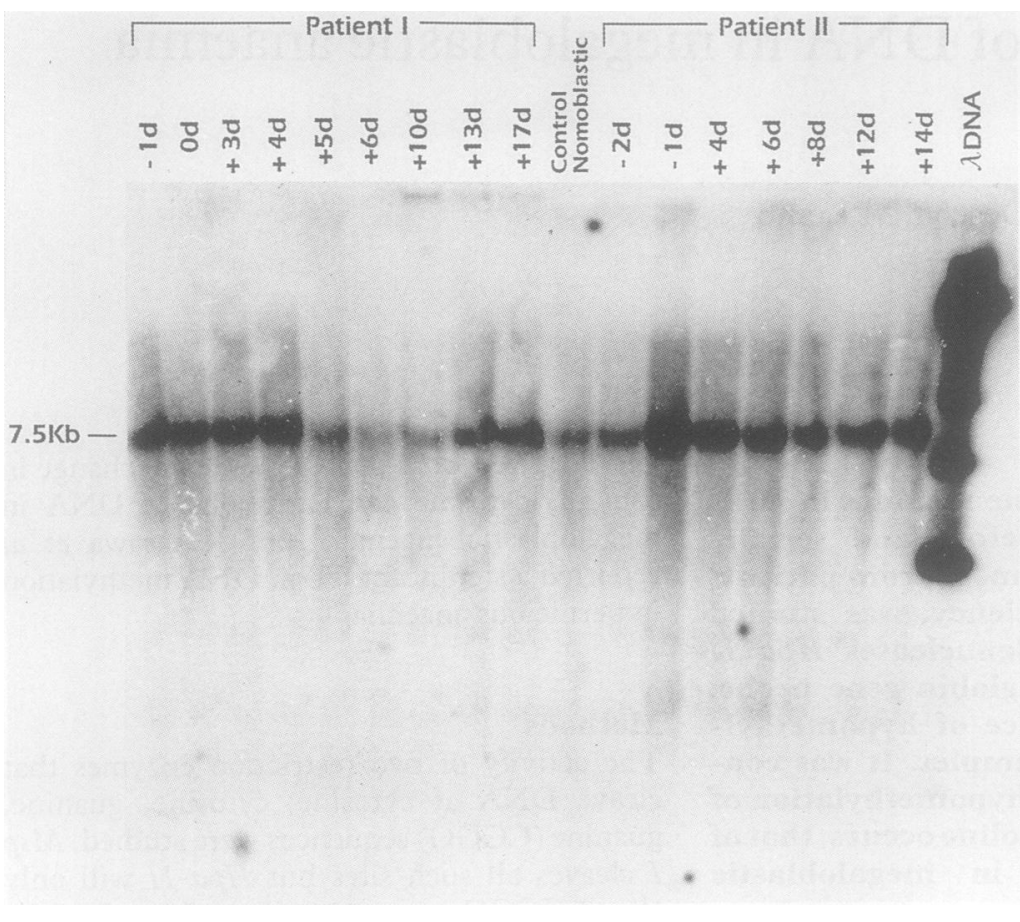

Southern blot analysis of leucocyte DNA from two patients with pernicious anaemia and a normoblastic control after Hind III/Hpa II digestion and hybridisation to an erglobin gene probe. $A D N A$ cleaved with Hind III was used as fragment size marker. The times before and after vitamin B12 treatment are shown. Samples were collected for two days before treatment $(-1 d, 0 d)$ and up to 17 days after treatment.

four patients using both marrow and leucocyte DNA. There was no difference in results between normoblastic and megaloblastic marrows.

\section{Discussion}

We failed to show hypomethylation of DNA in megaloblastic anaemia. Similar results were obtained by Dr R Green in Cleveland, USA (personal communication). On the other hand, impaired methylation of phospholipids is well established. ${ }^{1210}$

The cell seems to have priorities in the use of limited metabolic products. Utilisation of formate for purine synthesis is therefore impaired but further analysis shows that this applies only to guanine synthesis; synthesis of adenine is well maintained. ${ }^{2}$ This presumably reflects the essential role of adenine in coenzyme function such as adenosine diphosphate and nicotinamide adenine dinucleotide phosphate, etc. Similarly, it seems that methylation of DNA is preserved but that of less vital structures such as some phospholipids is left hypomethylated.

1 Arnstein HRV, Neuberger A. The effect of cobalamin in the quantitative utilization of serine, glycine and formate for the synthesis of choline and methyl groups of methionine. Biochem J 1953;55:259-71.

2 Deacon R, Perry J, Lumb M, Chanarin I. Formate metabolism in the cobalamin-inactivated rat. Br J Haematol (in press).

3 Ley TJ, DeSimone J, Anagnou NP, et al. 5-Azacytidine selectively increases $\gamma$ globin synthesis in a patient with $\beta^{+}$thalassemia. $N$ Engl J Med 1982;307:1469-75.

4 Zacharias W, O'Connor TR, Larson JE. Methylation of cytosine in the 5-position alters the structural and energetic properties of the supercoil-induced $Z$-helix and B-Z juntions. Biochemistry 1988;27:2970-8.

5 Hoffbrand AV, Pegg AE. Base composition of normal and megaloblastic bone marrow DNA. Nature (Lond) 1972;235:187-8.

6 Karasawa M, Tsukamoto N, Yamauchi H, Iwata N, Omine $M$, Maekawa T. DNA methylation in bone marrow cells from human megaloblastic anemia due to vitamin $B_{12}$ deficiency. Exp Hematol 1987;15:490.

7 Maniatis T, Fritsch EF, Sambrook J. Molecular cloning-a laboratory manual. New York: Cold Spring Harbor Laboratory, 1982

8 Fey MF, Pilkington SP, Summers C, Wainscoat S. Molecular diagnosis of haematological disorders using DNA from stored bone marrow slides. $\mathrm{Br} J$ Haematol 1987;67:489-92.

9 Southern EM. Detection of specific sequences among DNA fragments separated by gel electrophoresis. J Mol Biol 1975;92:503-17.

10 Jägerstad $M$, Âkesson B, Fehling $C$. Effect of methionine on the metabolic fate of liver folates in vitamin $B_{12}$-deficient rats. Br J Nutr 1980;44:361-9. 